\title{
SÍNTESE DE HETEROCICLOS BIOATIVOS DERIVADOS DO FERROCENO
}

Claudio M. P. Pereira* e Dalila Venzke

Centro de Ciências Químicas Farmacêuticas e dos Alimentos, Universidade Federal de Pelotas, 96010-900 Pelotas - RS, Brasil

Gustavo H. G. Trossini

Departamento de Farmácia, Faculdade de Ciências Farmacêuticas, Universidade de São Paulo, 05315-970 São Paulo - SP, Brasil

Recebido em 9/10/11; aceito em 1/8/12; publicado na web em 28/11/12

SYNTHESIS OF BIOACTIVE HETEROCYCLIC FERROCENE DERIVATIVES. The discovery of ferrocene marked one of the points of departure for modern organometallic chemistry. In general, the compounds of ferrocene derivatives are widely applied in several areas. One of the most important applications of ferrocene is the development of more active drugs, especially in cases where there is resistance to current drugs. Bioactive agents containing ferrocene have proven effective in combating diseases such as cancer, malaria, HIV, Alzheimer and conditions caused by fungi and bacteria. In this context, the present paper aims to highlights the synthesis of heterocycles containing ferrocene moiety and their use in medicinal chemistry.

Keywords: ferrocene; drugs; heterocycles.

\section{INTRODUÇÃO}

O ferroceno é uma substância organometálica do tipo sanduíche e foi sintetizado, acidentalmente, por Pauson e Kealy em 1951. Na busca pela síntese do fulvaleno, Pauson e Kealy promoveram a reação do ciclopentadieno e o reagente de Grignard formando o brometo de ciclopentadienilmagnésio e, em seguida, adicionaram o cloreto férrico obtendo uma substância de coloração vermelho-alaranjado de notável estabilidade, o ferroceno (Esquema 1).

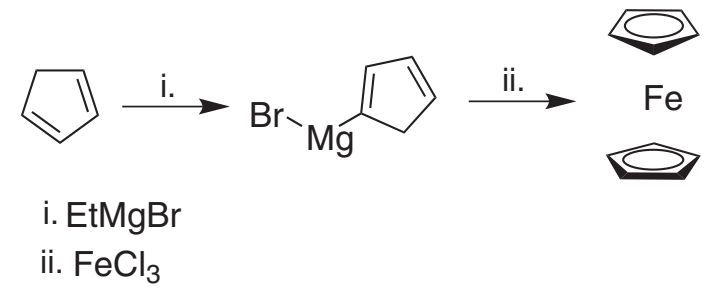

Esquema 1. Síntese do ferroceno

Entretanto, a estrutura confirmada da substância foi apresentada somente mais tarde, em duas publicações independentes: uma por Fischer e Pfab; a outra por Wilkinson, Rosenblum, Whiting e Woodward. Posteriormente, a substância foi denominada de ferroceno por Woodward. ${ }^{1-3} \mathrm{~A}$ descoberta do ferroceno impulsionou as pesquisas de compostos organometálicos. ${ }^{4} \mathrm{O}$ grupamento ferroceno exibe interessantes propriedades químicas e ao ser inserido em estruturas orgânicas pode produzir derivados com importantes aplicações e, além disso, apresenta baixo custo. ${ }^{5-7} \mathrm{O}$ ferroceno apresenta propriedades de oxirredução, ou seja, é capaz de sofrer oxidação reversível, ocorrendo a geração de espécie, cátion-radical como mostrado no Esquema 2. O ferroceno obedece a regra dos 18 elétrons e, desse total, 12 elétrons encontram-se em orbitais ligantes e os outros 6 em orbitais não ligantes. Os elétrons não ligantes determinam propriedades importantes do ferroceno como seu potencial redox, além de outras propriedades químicas. ${ }^{8}$

*e-mail: claudio.martin@pq.cnpq.br

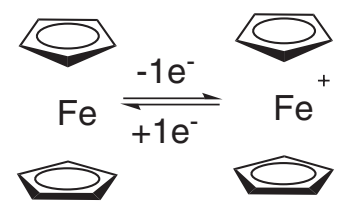

Esquema 2. Mecanismo de oxirredução do ferroceno

Uma das aplicações do ferroceno está baseada na sua capacidade de absorver radiação. Deste modo, um cromóforo de ferroceno confere uma coloração brilhante variando de amarelo-alaranjado a azul-esverdeado e esses produtos são firmemente fixados em vários materiais, incluindo produtos sintéticos. Tudo isso torna possível se empregar os derivados do ferroceno como corantes, materiais fotográficos e sensibilizadores de luz. ${ }^{910}$ Outra aplicação importante está baseada na habilidade do ferroceno e seus derivados de regular os processos de combustão, o que leva a possibilidades de uso como anti-incrustantes e agentes antidetonantes. ${ }^{4}$

Devido à capacidade do ferroceno sofrer oxidação reversível, compostos derivados de ferroceno têm sido usados como resinas trocadoras de elétrons. ${ }^{4,11}$ Também podem atuar como quimiossensores de ânions, ${ }^{12}$ biossensores, ${ }^{13,14}$ catalisadores, ${ }^{15}$ polímeros ${ }^{16,17}$ e grupo redox informativo em métodos eletroquímicos para detectar uma sequencia de ácidos nucleicos de doenças hereditárias e anomalias genéticas, pois o ferroceno mostrou ser estável durante a síntese de DNA e possuir um potencial redox acessível. ${ }^{18,19} \mathrm{O}$ ferroceno também tem atraído atenção especial na Química Medicinal por sua alta estabilidade, apresentar propriedades redox e sua não toxicidade..$^{20-22}$ Testes agudos e crônicos com o ferroceno e seus derivados atestaram sua relativa não toxicidade em mamíferos de várias espécies, como cães, ratos, camundongos e macacos. ${ }^{23-25}$ Bioativos contendo ferroceno têm se tornado eficientes contra doenças em que há resistência a fármacos. ${ }^{26}$

\section{FERROCENO NA QUÍMICA MEDICINAL}

Na presente revisão foram selecionados trabalhos pertinentes à aplicação do ferroceno como grupamento foco nos estudos sintéticos de moléculas bioativas. 


\section{Antibacterianos - aspectos gerais e derivados sintéticos}

Devido o uso indiscriminado dos antibacterianos, principalmente as penicilinas e cefalosporinas, ocorreu o desenvolvimento de resistência, que acontece quando a bactéria evolui para combater o mecanismo de ação do fármaco. ${ }^{26} \mathrm{O}$ fenômeno da resistência bacteriana em diversos antibióticos impõe sérias limitações às opções para o tratamento de infecções bacterianas, representando uma ameaça para a saúde pública. ${ }^{27}$

Há três tipos de resistência bacteriana: resistência intrínseca ocorre quando a bactéria evolui para a produção de uma enzima capaz de degradar o fármaco, por exemplo, a enzima $\beta$-lactamase; resistência por mutação - leva à alteração estrutural do microrganismo, impedindo as ações do fármaco; resistência mediada por plasmídio - envolve a passagem de informação da resistência por mutação de um microrganismo para outro. Assim, o DNA alterado é envolvido dentro de um plasmídio e pode ser transferido a outros organismos..$^{27,28}$

Nesse sentido, há uma busca sistemática para a síntese de novas substâncias eficazes no combate de bactérias. A inserção de um grupo ferroceno a essas substâncias tornou-se uma alternativa para combater a resistência, uma vez que em muitos casos os derivados ferrocenil são inibidores da enzima $\beta$-lactamase. ${ }^{27,28}$

\section{Sintese de antibacterianos contendo o grupo ferroceno}

$\mathrm{Na}$ busca por substâncias antibacterianas, Edwards et al. ${ }^{29}$ sintetizaram uma série de substâncias contendo o grupo ferroceno. Entre essas substâncias, as ferrocenil penicilinas e cefalosporinas 2, 3 e 9 preparadas pela reação do ácido 6-aminopenicilânico e 7-aminocefalosporânico, respectivamente, com anidrido 1 apresentaram pronunciada atividade antibacteriana (Esquema 3).

Penamas são heterociclos bicíclicos, onde anéis 1-3-tiazóis são fundidos com o anel azetidina. ${ }^{30}$ As penamas são caracterizados como uma classe de antibióticos -lactâmicos que têm uma estrutura híbrida entre penicilina e cefalosporina e apresentam grande atividade contra uma ampla faixa de bactérias. ${ }^{30}$ Em outro estudo, Long et al. ${ }^{31}$ mostraram a síntese de novos derivados do ferroceno contendo penamos (Esquema 4). As substâncias obtidas foram preparadas a partir da reação da 4-acetoxiazetidinona $\mathbf{1 0}$ com acetiltiolatos de sódio gerando tioésteres 11a-h, seguida de formação de oxamatos 12a-h pela reação com alil cloro-oxalato na presença de di-isopropiletilamina. Posteriormente, foi feita a ciclização entre as substâncias 12a-h e $\mathrm{P}(\mathrm{OEt})_{3}$ na ausência de solvente. A solução foi concentrada sob pressão reduzida, o resíduo foi aquecido em álcool isobutílico, produzindo as substâncias 13a-h por filtração da mistura reacional em sílica gel. O tratamento das substâncias 13a-h com excesso de fluoreto ácido de amônio em dimetil formamida (DMF) e $n$-metilpirrolidona (NMP) à temperatura ambiente gerou as substâncias 14a-h. Esses compostos 14a-h foram reagidos com $\mathrm{NaHCO}_{3}$ na presença de acetato de paládio e trietil fosfato e originaram os carboxilatos correspondentes 15a-h e seus sais de sódio. Os autores realizaram o teste de atividade in vitro contra bactérias Gram-positivas e Gram-negativas, incluindo cepas de Staphylococcus aureus resistentes à meticilina. A maioria das penamas sintetizadas apresentou potencial atividade antibacteriana comparável à do fármaco comercial faropenem. Em particular, o composto $15 \mathrm{~h}$ contendo um grupo heterocíclico apresentou maior atividade antibacteriana frente às cepas testadas, com valores de $\mathrm{IC}_{50}$ entre $0,1-28,8 \mu \mathrm{g} / \mathrm{mL}$.

Pirazóis são heterociclos de grande representatividade na Química Medicinal. A síntese dessas substâncias tem sido extensivamente reportada, ${ }^{30-32}$ e o emprego de tecnologias alternativas para preparação desses núcleos tem sido bem explorado, como, ultrassom, ${ }^{33,34}$ micro-ondas ${ }^{35-37}$ e, ainda, engloba o uso de solventes biorrenováveis, como o etanol..$^{38}$ Devido a isso, Fang et al. ${ }^{39}$ prepararam pirazóis ferrocenil
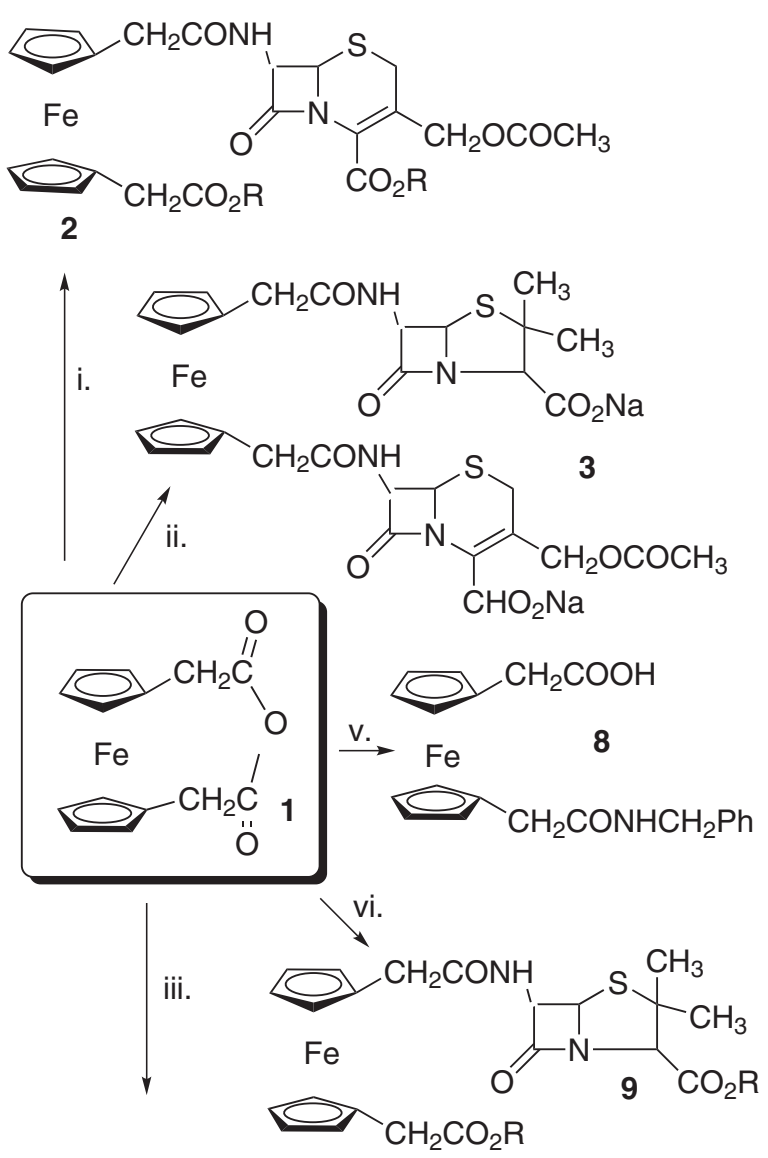

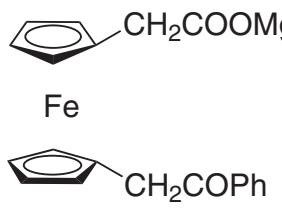

4

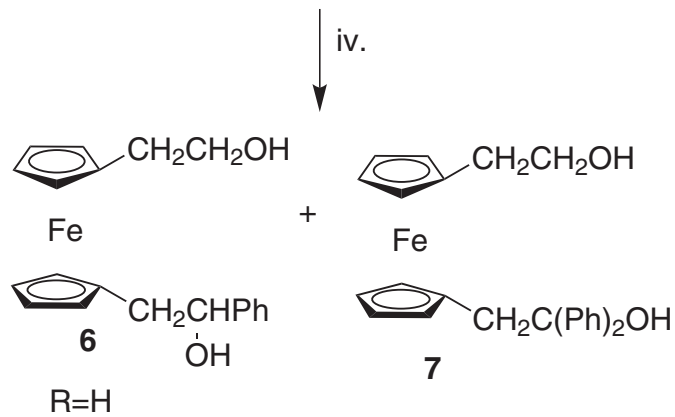

i. 7-ACA/ET 3 N ii. 6-APA-SiMe3, EtOC(O)Cl, 7-ACA

iii.PhMgBr

iv. Hidreto de bis(2-metoxietoxi)alumínio, $\mathrm{H}_{2} \mathrm{O}$

v. $\mathrm{PhCH}_{2} \mathrm{NH}_{2}$ vi.6-APA

Esquema 3. Síntese de penicilinas e cefalosporinas derivadas do ferroceno

derivados 21-23 e avaliaram sua atividade antibacteriana. A síntese foi efetuada via a condensação de propenonas com fenilidrazina. Em especial, as propenonas utilizadas $\mathbf{1 9}$ e $\mathbf{2 0}$ foram sintetizadas a partir da reação de $\alpha$-haloacetilferroceno 16 e 17, 1,2,4-triazol e carbonato de potássio como base, gerando o $\alpha$-triazolilacetilferroceno 18 , sendo condensado com benzaldeídos substituídos (Esquema 5 e 6). A atividade antibacteriana das substâncias 21 a-g in vitro contra Isariopsis 


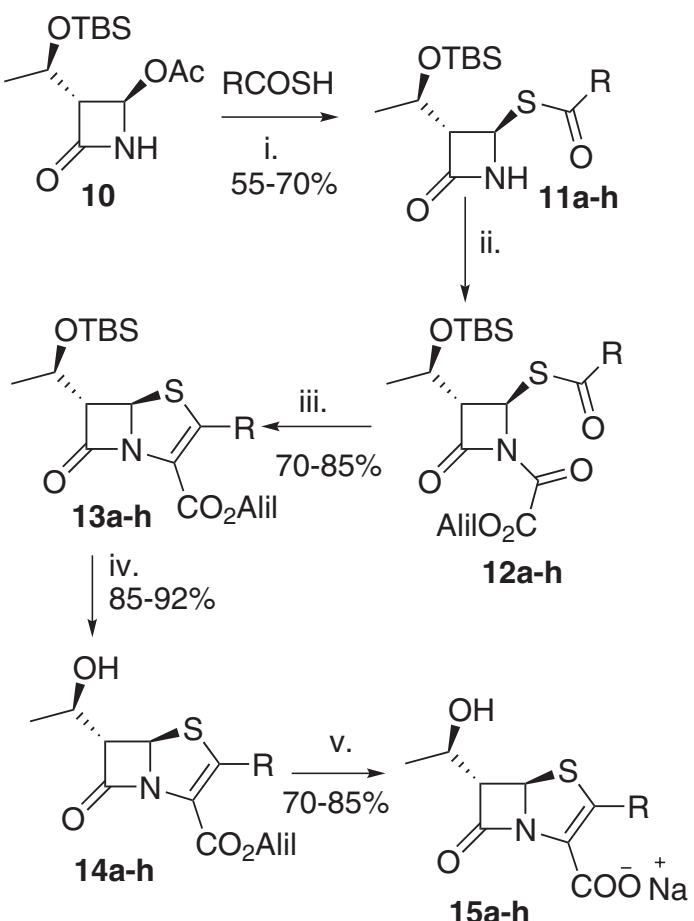

$\mathrm{R}$ :

a $-\mathrm{Fc} \quad$ b $-\mathrm{CH}_{2} \mathrm{Fc} \quad$ c $-\mathrm{CH}_{2} \mathrm{CH}_{2} \mathrm{Fc}$

d $-\mathrm{CH}_{2} \mathrm{CH}_{2} \mathrm{CH}_{2} \mathrm{Fc}$<smiles>COc1cc(I)ccc1F</smiles><smiles>Cc1ccc2cc(F)ccc2c1</smiles><smiles>[3H]c1ccc(C)o1</smiles><smiles></smiles>

$\mathrm{Fe}$

i. $\mathrm{NaOH}, \mathrm{CH}_{2} \mathrm{Cl}_{2}$ ii.ClCOCO${ }_{2}$ Alil, i- $\mathrm{Pr}_{2} \mathrm{NEt}$

iii.P(OEt) ${ }_{3}, 60^{\circ} \mathrm{C}$, então i-butil alcool, $90^{\circ} \mathrm{C}$ iv. $\left(\mathrm{NH}_{4}\right) \mathrm{HF}_{2}$, DMF-NMP

v.Pd(OAc) $)_{2}, \mathrm{P}(\mathrm{OEt})_{3}$, dimedona, $\mathrm{NaHCO}_{3}$

Esquema 4. Síntese de penemas ferrocenil derivados

clavispora, Bremia lactucae, Cladosporium fulvum, Erysiphe graminis e Alternaria mali não foi encorajadora quando comparada aos produtos comerciais, apresentando uma razão inibitória relativa com variação de 0 a $22,2 \%$.

Nessa linha de estudo, Zhang propôs a síntese de ferrocenil-tiazola-acil-hidrazonas pela reação do ácido 4-metiltiazol-5-carboxílico 24 em metanol e meio ácido, gerando a substância metil 4-metiltiazol-5-carboxilato 25 e esse, pela reação com hidrazina em etanol, formou a 4-metiltiazol-5-carbo-hidrazida 26. Logo após, realizou-se a condensação da hidrazida com formilferroceno ou acetilferroceno na presença de uma quantidade catalítica de ácido acético, obtendo-se ferrocenil-tiazolacilhidrazonas $\mathbf{2 7}$ e 28 (Esquema 7). As substâncias 26, 27 e 28 apresentaram atividade contra Staphylococcus aureus, Esherichia coli e Pseudomonas aeruginosa, com valores de concentração mínima inibitória entre 25,0-100 $\mu \mathrm{g} / \mathrm{mL} .^{40}$

Damljanović et al. ${ }^{41}$ sintetizaram uma série de derivados de

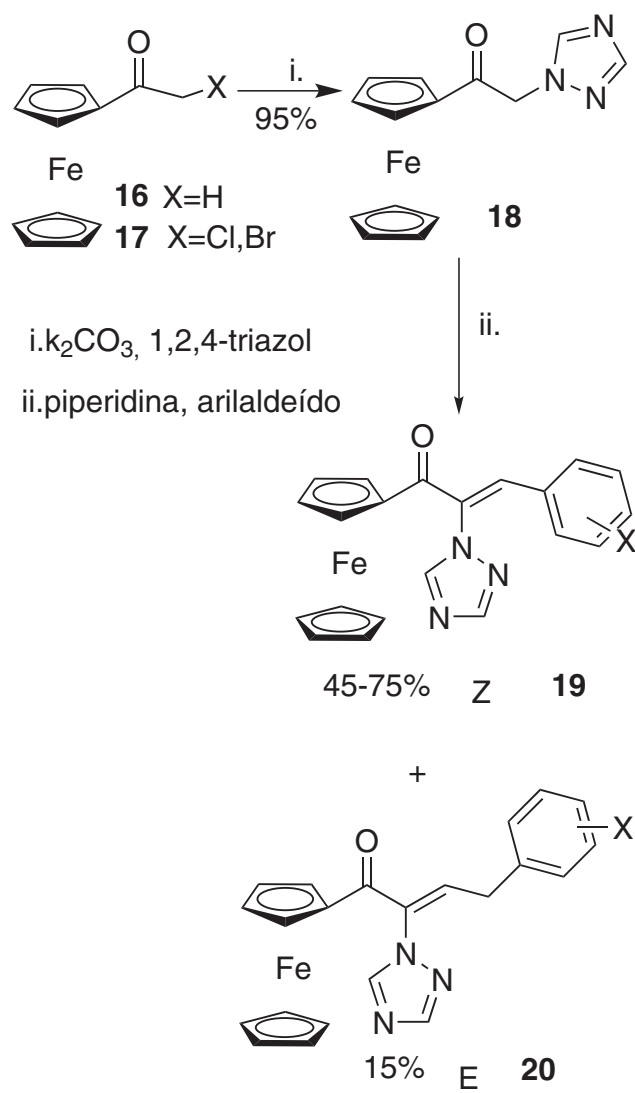

Esquema 5. Síntese de propenonas

pirazóis através da condensação do $1 H$-3-ferrocenil-1-fenil-pirazol4-carboxaldeído com aminas usando etanol como solvente, seguida pela redução com boro hidrato de sódio. A substância $1 H$-3-ferrocenil1-fenil-pirazol-4-carboxaldeído $\mathbf{3 1}$ foi previamente sintetizada de acordo com metodologia descrita por Joksovic' et al.. ${ }^{42}$ As substâncias foram testadas quanto às atividades antibacteriana e antifúngica, onde as substâncias $32\left(\mathrm{IC}_{50}=46-97 \mu \mathrm{g} / \mathrm{mL}\right)$ e $\mathbf{3 3}\left(\mathrm{IC}_{50}=61-98 \mu \mathrm{g} / \mathrm{mL}\right)$ se mostraram mais promissoras (Esquemas 8 e 9).

\section{Antifúngicos - aspectos gerais e derivados sintéticos}

Atualmente, a prevalência por infecções fúngicas sistêmicas tem crescido devido não só à utilização abundante de antibióticos de amplo espectro, mas, também, por causa de alterações no sistema imunológico associadas ao vírus do HIV, à terapia do câncer e ao transplante de órgãos. Considerando que ainda há um pequeno número de estudos e substâncias demonstrando ação antifúngica, torna-se necessário buscar novas alternativas de síntese de novos protótipos. ${ }^{43,44}$

\section{Síntese de antifúngicos ferrocenil substituídos}

Dentre os sistemas heterocíclicos, os triazóis e derivados têm despertado grande interesse devido às suas importantes propriedades farmacológicas. ${ }^{45}$ Dessa forma, tem-se buscado novas alternativas de síntese mais eficazes para essas substâncias. Nesse sentido, em 2004, Jin et al. realizaram a síntese de derivados 1,2,4- $H$-triazóis ferrocenil substituídos a partir de propanonas contendo ferroceno, sintetizadas a partir do ferroceno via um intermediário de Mannich seguido de condensação e ciclização dessas propanonas com fenil hidrazina (Esquema 10). Sua atividade antifungicida foi avaliada contra cinco fungos selecionados, Pratylenchus zeae, Alternaria solani, Cladosporium fulvum, Physalospora piricola e C. ara. As substâncias 59-62 contendo os grupamentos triazol e pirazol (razão 


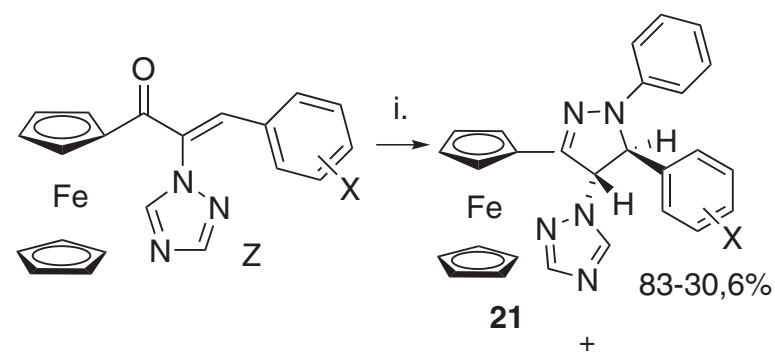<smiles>O=C(C(=C(Nc1ccccc1)c1ccccc1)n1cncn1)c1ccccc1</smiles>

22<smiles>[X]c1ccccc1CC=C(C(=O)c1ccccc1F)n1cncn1</smiles>

E<smiles>[X]c1ccc(C=N)cc1</smiles>

23

$$
\begin{aligned}
& \mathrm{X}=\mathbf{a} \mathrm{H} \text { d } 4-\mathrm{Cl} \text { g } 4-\mathrm{OCH}_{3} \\
& \text { b } 2-\mathrm{Cl} \text { e } 2,4-\mathrm{Cl}_{2} \\
& \text { c } 3-\mathrm{Cl} \text { f } 4-\mathrm{CH}_{3}
\end{aligned}
$$

i. $\mathrm{NH}_{2} \mathrm{NHPh}, \mathrm{AcOH}, \mathrm{EtOH}$

Esquema 6 . Síntese das substâncias 1-fenil-3-ferrocenil-4-triazolil-5-aril-di-hidropirazóis ferrocenil derivados<smiles>COC(=O)c1sc([AsH2])nc1C</smiles><smiles></smiles>

$27 \mathrm{H}$

$28 \mathrm{CH} 3$

i. $\mathrm{H}_{2} \mathrm{SO}_{4}, \mathrm{MeOH}$

ii. $\mathrm{N}_{2} \mathrm{H}_{4} \cdot \mathrm{H}_{2} \mathrm{O}$, EtOH

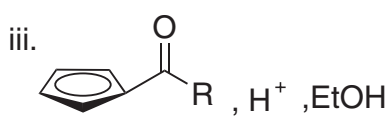

$\mathrm{Fe}$

Esquema 7. Síntese de ferrocenil-tiazolaacil-hidrazonas

inibitória relativa de 0 a $35 \%$ ) apresentaram maior atividade que as substâncias 45-58 (razão inibitória relativa de 0 a 40\%). ${ }^{46}$

Biot et al. ${ }^{47}$ prepararam um análogo do fluconazol, o ferroceno-fluconazol, e investigaram seu potencial antifúngico para a atividade

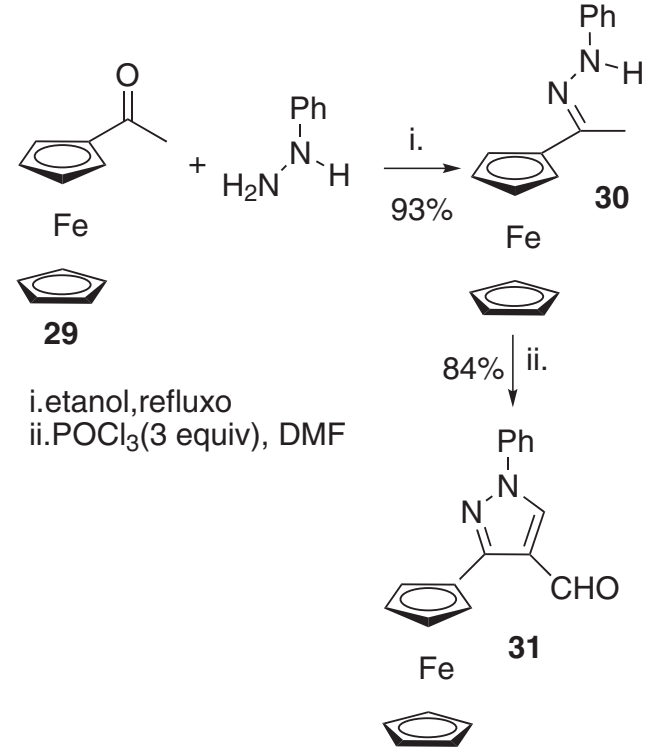

Esquema 8. Síntese do 1H-3-ferrocenil-1-fenil-pirazol-4-carboxaldeído<smiles>[R]N=Cc1cn(-c2ccccc2)nc1-c1ccccc1OC(O)Cc1cn(-c2ccccc2)nc1-c1ccc(F)cc1</smiles>

i. $\mathrm{NaBH}_{4}$

$\mathrm{R}=$

$32\left(\mathrm{CH}_{3}\right)_{3} \mathrm{C}-$

33<smiles>CC1CCCC1</smiles><smiles>[2H]NCc1cn(-c2ccccc2)nc1-c1ccccc1</smiles>

34<smiles>CCc1ccccc1</smiles>

38<smiles>Cc1ccccc1</smiles>

35<smiles>CCc1cccnc1</smiles>

39<smiles>CC(=O)Nc1ccc(C)cc1</smiles>

36

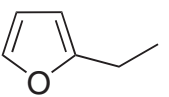

37<smiles>CCc1cccs1</smiles>

40

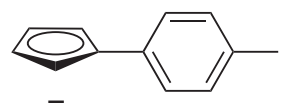

$\mathrm{Fe}$

$\mathrm{Fe}$

$32-40$
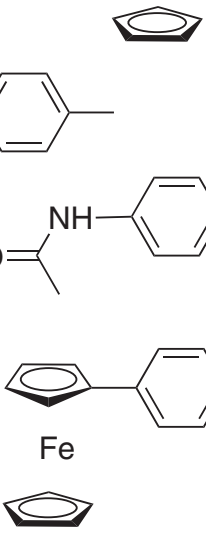

Esquema 9. Síntese de derivados de pirazóis

in vitro do ferroceno-fluconazol e fluconazol, avaliada contra uma série de cepas de Candida ssp., inclusive as mais resistentes ao fluconazol. A síntese desse análogo foi feita utilizando o ferroceno como reagente de partida. Na primeira etapa foi feita a metalação do ferroceno na presença de $t$-butil-lítio, gerando o ferroceno litiado e esse, por reação subsequente com 1,3-dicloroacetona, produziu o produto halogenado 64. Posteriormente, o produto halogenado 64 e o 1,2,4-triazol foram aquecidos a $70{ }^{\circ} \mathrm{C}$ por $19 \mathrm{~h}$ 


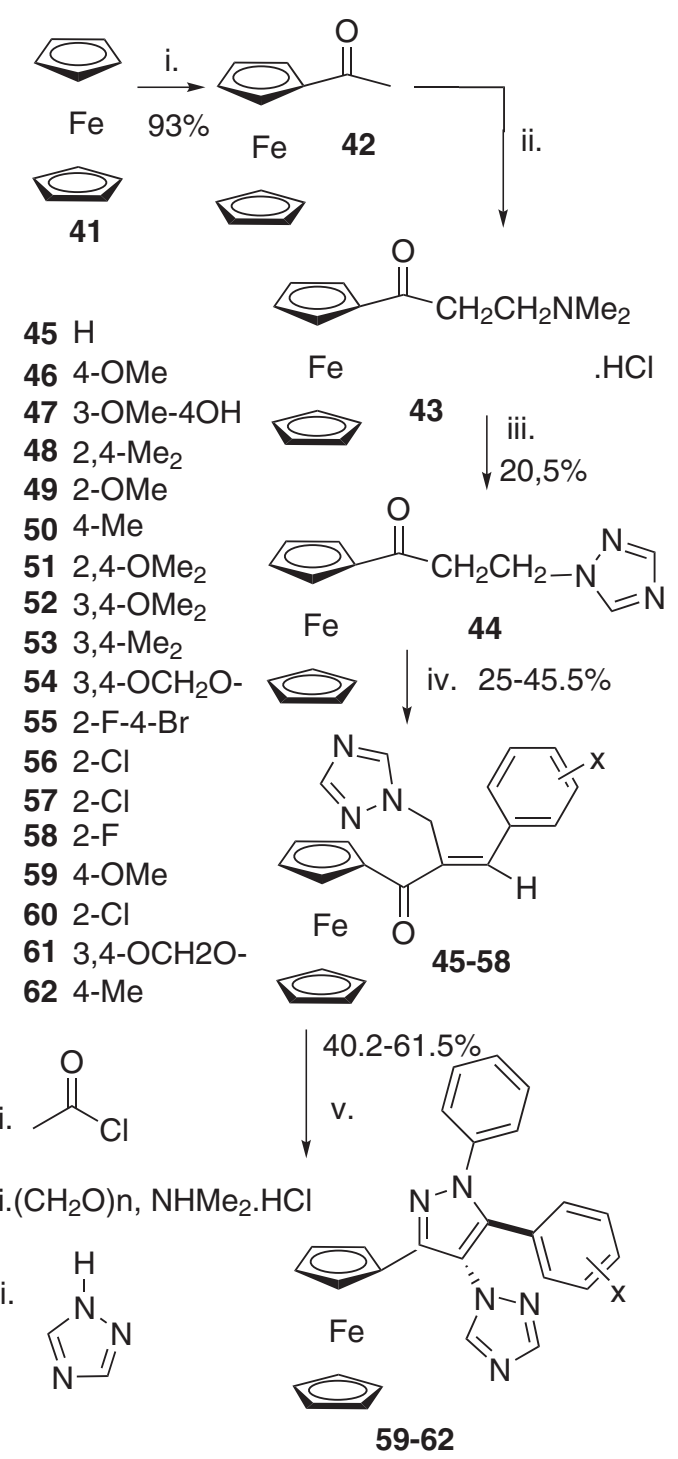

iv. $\mathrm{ArCHO} /$ piperidina/ácido acético

V.<smiles>CCOC(=O)OCCOCCO</smiles>

Esquema 10. 1,2,4-H-Triazóis ferrocenil-substituídos

em $N, N$-dimetilformamida na presença de carbonato de potássio, obtendo-se então o análogo ferroceno-fluconazol 67 e um subproduto 66 pela condensação incompleta (Esquema 11).

Os resultados encontrados no teste de atividade biológica mostraram que a adição do ferroceno-fluconazol não influenciou no crescimento dos fungos em comparação ao fluconazol. Quando o ferroceno-fluconazol foi adicionado ao fluconazol houve uma reversão da atividade inibitória do fluconazol.

\section{Antimaláricos - aspectos gerais e derivados sintéticos}

A malária é uma das mais problemáticas infecções no mundo. Há quatro espécies de parasitas que causam a malária humana Plasmodium falciparum, P. vivax, P. ovale e P. malariae - sendo que o mais perigoso é o Plasmodium falciparum. Alguns fármacos conhecidos utilizados contra a malária são a cloroquina, mefloquina e quinina. ${ }^{48,49} \mathrm{O}$ mosquito Plasmodium falciparum se tornou resistente a esses fármacos. Desta forma, a síntese de novos antimaláricos

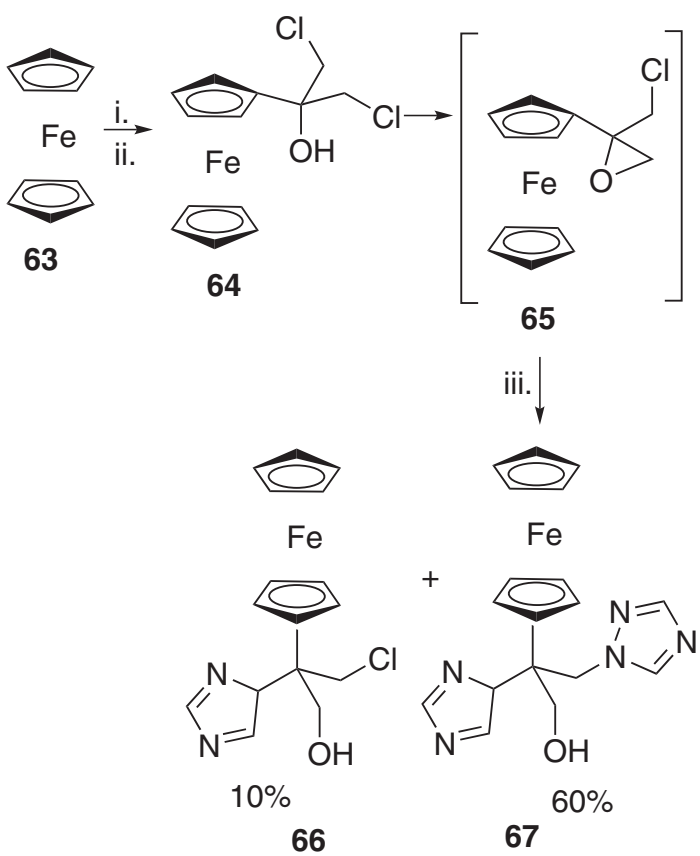

i.t-BuLi, THF, $0^{\circ} \mathrm{C}$

ii. $\left(\mathrm{ClCH}_{2}\right)_{2} \mathrm{CO}, \mathrm{Et}_{2} \mathrm{O},-78^{\circ} \mathrm{C}, \mathrm{CH}_{3} \mathrm{COOH}, 0^{\circ} \mathrm{C}$ iii.1,2,4-triazol, $\mathrm{k}_{2} \mathrm{CO}_{3}, \mathrm{DMF}, 70^{\circ} \mathrm{C}$

Esquema 11. Síntese de análogo do fluconazol

contendo o grupo ferroceno tem atraído muito interesse por parte de pesquisadores. ${ }^{22,50,51} \mathrm{Em}$ especial, a ferroquina mostrou ser eficiente no combate quando há a resistência à cloroquina (Figura 1). ${ }^{52}$<smiles>[X]CCN(CC)CCCC(C)Nc1ccnc2cc(Cl)ccc12</smiles><smiles>CN(C)Cc1ccccc1CNc1ccnc2cc(Cl)ccc12</smiles>

Figura 1. Estruturas da cloroquina, hidroxicloroquina e ferroquina

Síntese de antimaláricos contendo ferroceno

Devido à alta atividade da ferroquina no combate à malária, muitos pesquisadores vêm investigando a síntese de novas substâncias antimaláricas contendo ferroceno susbtituído. ${ }^{22,50,51}$ Biot et al. reportaram a síntese de uma série de hidroxil ferrocequinas derivadas 70-72 que foram obtidas via a quaternização do nitrogênio terminal da ferroquina com iodeto de metila em acetona à temperatura ambiente. O sal de amônio quaternário resultante é um grupo de saída que pode ser substituído por um aminoálcool apropriado em refluxo de acetonitrila (Esquema 12). As substâncias 70-72 foram mais ativas que a cloroquina, mostrando valores de $\mathrm{IC}_{50}$ de 11,7 a $30 \mathrm{nM} .^{52}$

Outros derivados do ferroceno (Esquema 13) foram preparados a partir de triazaciclononanos e sua atividade antiplasmódica foi testada 
<smiles>CN(C)Cc1ccccc1CNc1ccnc2cc(Cl)ccc12</smiles><smiles>CN(C)Cc1ccccc1CNc1ccnc2cc(Cl)ccc12</smiles><smiles>[R]N(CCO)Cc1ccccc1CNc1ccnc2cc(Cl)ccc12</smiles>

i. $\mathrm{CH}_{3}$ l, acetona ii. $\mathrm{HOCH}_{2} \mathrm{CH}_{2} \mathrm{NHR}, \mathrm{CH}_{3} \mathrm{CN}$

$70 \mathrm{R}=\mathrm{H} \quad 71 \mathrm{R}=\mathrm{CH}_{3}$

$72 \mathrm{R}=\mathrm{C}_{2} \mathrm{H}_{5}$

Esquema 12. Síntese de hidroxil ferrocequinas derivadas

contra cepas (HB3) e (Dd2) do Plasmodium falciparum. Entre as substâncias sintetizadas, a substância $77\left(\mathrm{IC}_{50}=62 \mathrm{nM}\right)$ apresentou maior atividade in vitro contra cepas resistentes da cloroquina (Dd2). ${ }^{53}$

Em trabalho publicado por Wu et al. foi mostrada a síntese de chalconas ferrocenil derivadas por meio de uma condensação de ClaisenSchmidt. Além disso, foi avaliada a atividade antiplasmódica dessas substâncias. A substância mais ativa foi a 1-ferrocenil-3-(4-nitrofenill) prop-2-en-1-ona 81 com valor de $\mathrm{IC}_{50}=5,1 \mu \mathrm{M}$ (Esquema 14). ${ }^{54}$

Biot et al. ${ }^{55}$ desenvolveram uma rota sintética para deuteração de derivados do ferroceno, objetivando a síntese de 8-deutério-7-cloro-4-[(3-deutério-2- $N, N$-dimetilaminometil)- $N$-ferrocenilmetilamino]quinolina, um agente antimalárico. Esta síntese foi feita, primeiramente, pela metalação da $N, N$-dimetil(ferrocenilmetil)amina na presença de $t$-butil-lítio. O derivado obtido foi então reagido com óxido de deutério, gerando a $N, N$-dimetil(2-deuterioferrocenilmetil)amina. Essa substância foi convertida a 3-deutério-2-( $N, N$-dimetilaminometil) ferocenocarboxaldeído e, depois, à correspondente amina primária 84 via oxima (Esquema 15).

A dicloroquinolina deuterada $\mathbf{8 6}$ foi sintetizada pelo tratamento da 4,7-dicloroquinolina em óxido de deutério com ácido sulfúrico deuterado (Esquema 16).

A condensação das substâncias 87 e 88 em N-metil-2-pirolidinona produziu 8-deutério-7-cloro-4-[(3-deutério-2-N,N-dimetilaminometil)-N-ferrocenilmetilamino] quinolina 89 (Esquema 17).

\section{Inibidores de acetilcolinesterase - aspectos gerais e derivado sintético}

A doença de Alzheimer é a patologia neurodegenerativa associada à idade, para a qual há pouco tempo não tinha tratamento eficaz.

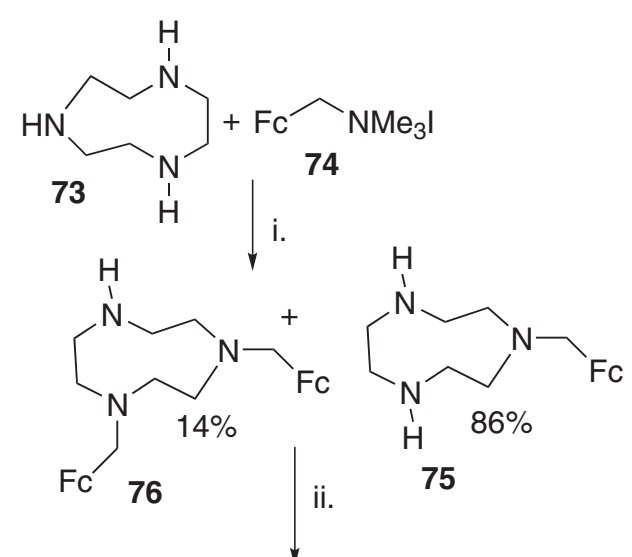<smiles></smiles>

$68 \%$

i) 5 equiv. $\mathrm{K}_{2} \mathrm{CO}_{3}, \mathrm{H}_{2} \mathrm{O}$, refluxo, 3h.

ii) 5 equiv. 4,7-dicloroquinolina,<smiles>CCN(CC)CCN(CCF)CCN(CCN(CC)CC)c1ccnc2cc(Cl)ccc12</smiles>

$32 \%$

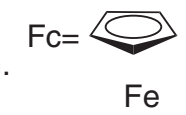

Esquema 13. Esquema de síntese de triazaciclononanos ferrocenil derivados
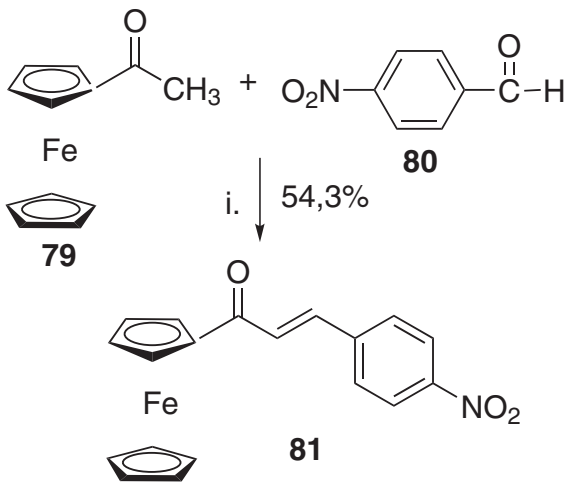

i. $\mathrm{KOH}$, etano

Esquema 14. Síntese da chalcona ferrocenil substituída

Estudos comprovaram que pacientes com essa doença têm os sistemas cerebrais que utilizam a colina gravemente destruídos, o que deu suporte para a introdução terapêutica de base colinérgica da doença. Desta forma, substâncias inibidoras de acetilcolinesterase mostraram ser úteis no combate a essa doença. A tacrina foi o primeiro inibidor de acetilcolinesterase aprovado para o tratamento da Alzheimer. Entretanto, o uso desse fármaco é limitado, pois apresenta uma série de efeitos adversos..$^{56,57}$

\section{Síntese de inibidor da acetilcolinesterase}

Contelles et al. sintetizaram derivados 4-ferrocenil-4H-piran e 4-ferrocenil-4-di-hidropiridina. A síntese da substância 92 foi efetuada pela reação do acetoacetato de etila e ferrocenomalonodinitrila 


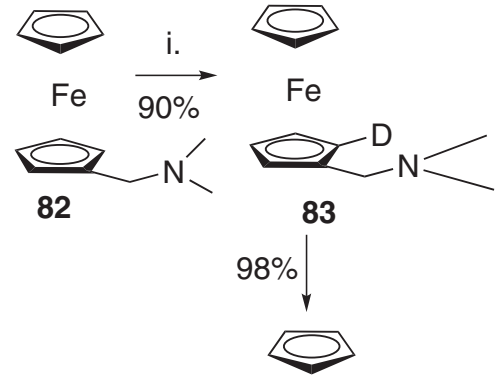

$\mathrm{Fe}$

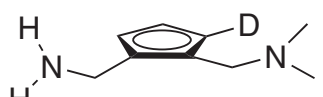

84

i. 1-tBuLi,Et ${ }_{2} \mathrm{O}, 2-\mathrm{D}_{2} \mathrm{O}$

ii. 1-tBuLi, $\mathrm{Et}_{2} \mathrm{O}$ 3- $\mathrm{NH}_{2} \mathrm{OH} . \mathrm{HCl}$ 2-DMF, $\mathrm{Et}_{2} \mathrm{O} \quad \mathrm{NaOH}, \mathrm{EtOH}$

Esquema 15. Síntese da amina primária<smiles>[2H]c1c(Cl)ccc2c(Cl)ccnc12</smiles>

Esquema 16. Preparação da dicloroquinolina deuterada<smiles>Clc1ccc2c(Cl)ccnc2c1Br</smiles><smiles>[2H]c1cccc(F)c1CN(C)C</smiles>

i. NMP, TEA $\mathrm{K}_{2} \mathrm{CO}_{3}$

i. $44 \%$

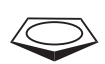

$\mathrm{Fe}$<smiles>[2H]c1cccc(NCc2ccnc3c(Cl)cccc23)c1</smiles>

Esquema 17. 8-deutério-7-cloro-4-[(3-deutério-2-N,N-dimetilaminometil)-Nferrocenilmetilamino] quinolina

catalisada por piperidina. A substância (Esquema 18) 92 isolada foi transformada no períneo $\mathbf{9 3}$ por simples tratamento com anidrido acético em piridina. ${ }^{58}$

No Esquema 19 é mostrada a reação de Friendlär para obtenção dos produtos 94 e 95, através da reação do produto 93 com cicloexanona ou ciclo-heptanona.

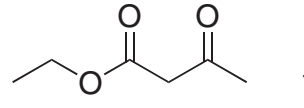<smiles>N#C/C=C/c1ccccc1</smiles>

90

91

$\mathrm{Fe}$

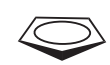

i. $51 \%$

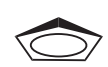

$\mathrm{Fe}$

$\mathrm{Fe}$<smiles>CCOC(=O)C1=C(C)OC(N(C)C)=C(C#N)C1c1ccccc1</smiles>

93

i.

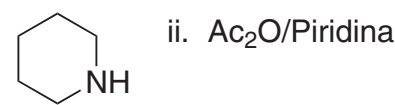

Esquema 18. Síntese do 4 H Piran

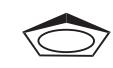<smiles>c1ccccc1</smiles>

$\mathrm{Fe}$

$\mathrm{Fe}$<smiles>[R]C1=C(C)OC(N)=C(C#N)C1c1ccccc1</smiles>

93

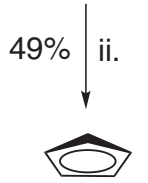

i.<smiles>O=C1CCCCC1</smiles>

$\mathrm{Fe}$<smiles>CCOC(=O)C1=C(C)Oc2nc3c(c(N)c2C1c1ccccc1)CCCC3</smiles>

ii.<smiles>O=C1CCCCCC1</smiles>

95

$\mathrm{R}=\mathrm{EtO}_{2} \mathrm{C}$

Esquema 19. Síntese de análogos da tacrina 34

As reações multicomponentes têm atraído crescente interesse dentro da Química Verde, pois nessas reações há economia de átomos, menor tempo de reação e menor quantidade de energia em cada reação. A reação de Hantzch é uma reação multicomponente, onde os produtos formados são derivados de 1,4-di-hidropiridinas e apresentam ampla atividade biológica. ${ }^{59}$ Contelles et al., no mesmo trabalho, também, efetuaram uma reação de Hantzch entre 
ferrocenocarboxaldeído, acetoacetato de etila e $\beta$-aminocrotonato, produzindo a di-hidropiridina 97 (Esquema 20). ${ }^{58}$

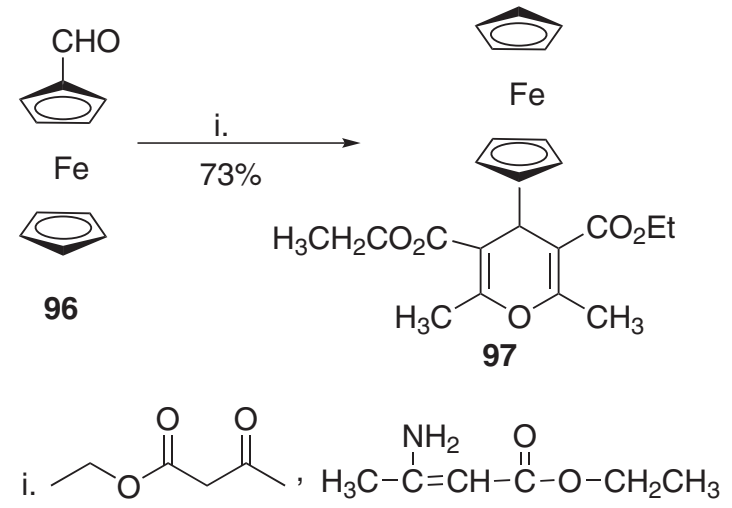

Esquema 20. Síntese de di-hidropiridina

As substâncias 94 e 95 possuem semelhança estrutural e funcional com a tacrina (Figura 2), primeiro fármaco utilizado primeiro fármaco utilizado no combate à doença de Alzheimer. Devido a isso, essas substâncias foram avaliadas quanto a sua capacidade inibitória da acetilcolinesterase, mostrando moderada inibição com valores de $\mathrm{IC}_{50}$ de 39 e $29 \mu \mathrm{M}$, respectivamente, sendo que a tacrina possui um $\mathrm{IC}_{50}$ de $0,14 \mu \mathrm{M}$.<smiles>Nc1c2c(nc3ccccc13)CCCC2</smiles>

Figura 2. Estrutura química da tacrina

\section{Anti-HIV - aspecto geral e derivado sintético}

Os vírus estão envolvidos em uma grande variedade de doenças crônicas e degenerativas, sendo responsáveis por mais de $60 \%$ das doenças causadas no homem. Um dos vírus mais estudados hoje em dia é o chamado vírus da imunodeficiência adquirida (HIV) ${ }^{60}$ Esse vírus, ao infectar os linfócitos TCD4+ conduz à falta de coordenação do sistema imunológico, acabando por estabelecer uma imunodeficiência.

Em 1996 foi apresentado o coquetel de fármacos usado no combate ao vírus HIV. Esse coquetel corresponde à combinação de medicamentos capazes de inibir diferentes etapas da replicação viral, sendo classificadas de acordo com as enzimas virais que inibem, dividindo-se nas categorias: inibidores de transcriptase reversa nucleosídeo-nucleotídeo; inibidores de transcriptase reversa não nucleosídeo e inibidores de protease.

Outras estratégias também têm sido adotadas na concepção de novas substâncias capazes de inibir diferentes pontos da replicação viral, como: inibidores de fusão; inibidores da proteína nucleocapsídica; inibidores da enzima integrase e inibidores da enzima de transcrição.

Apesar das dificuldades, o tratamento da Acquired Immuno Deficiency Syndrome (AIDS) através da quimioterapia avançou muito nos últimos anos. No entanto, a busca por fármacos mais potentes a diferentes tipos de resistência, com baixos efeitos colaterais e custos reduzidos tem sido objeto de intensa pesquisa e continua a ser uma área promissora. ${ }^{60,61}$

\section{Síntese de substância com atividade anti-HIV}

Champdoré e colaboradore ${ }^{20}$ incorporaram um grupo ferrocenometil em uma base heterocíclica, através de uma reação ambientalmente correta entre nucleotídeos e nucleosídeos e ferrocenometanol em meio aquoso (Esquema 21). As substâncias obtidas 99, 101 e 102 foram testadas com a finalidade de descobrir se apresentavam atividade citotóxica, antiviral, antifúngica e antimicrobiana.<smiles>Cc1cn(P)c(=O)n(CCC(F)(F)F)c1=O</smiles>

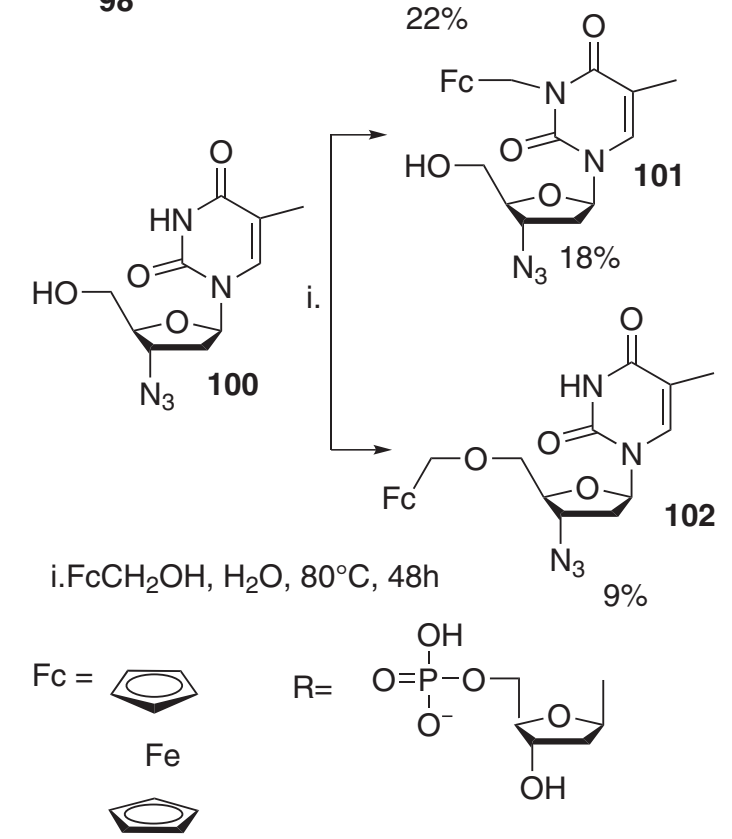

Esquema 21. Síntese de nucleotídeos e nucleosídeos ferrocenil substituídos

As substâncias 99, 101 e $\mathbf{1 0 2}$ possuindo timina apresentaram significativa atividade citotóxica contra células MT-4 com valores de citotoxicidade de 49, 29 e $53 \mu \mathrm{M}$, respectivamente. Dentre as substâncias testadas, os derivados contendo $3^{\prime}$-deoxi-3'- $\alpha$-azidotimidina $\mathbf{1 0 1}$ e $\mathbf{1 0 2}$ mostraram-se mais efetivos contra HIV, entretanto foram muito menos ativos quando comparados ao fármaco padrão. As substâncias sintetizadas mostraram-se inativas frente a outros testes contra alguns vírus, fungos e bactérias.

\section{Antitumorais - aspectos gerais e derivados sintéticos}

O câncer é uma doença caracterizada pelo crescimento celular descontrolado e sua capacidade de invadir outros tecidos. O câncer de mamaé o mais comum entre o sexo feminino e afeta uma em cada 8 mulheres. Em geral, o câncer de mama pode ser dividido em dois grupos discriminados pela presença ER(+) ou ausência ER(-) do estrogênio receptor. Cerca de $2 / 3$ de todos os casos são do tipo ER(+), que é suscetível à terapia hormonal por moduladores do estrogênio receptor. No caso $\mathrm{ER}(+)$ há dois subtipos de receptores, $\mathrm{ER} \alpha$ e ER $\beta$. Os primeiros fármacos usados para essa doença foram tamoxifeno, hidroxitamoxifeno e raloxifeno (Figura 3). O tamoxifeno age, in vivo, como poderoso agente citostático, pois compete pela ligação ao $\mathrm{ER} \alpha$ e impede a transcrição de DNA no tumor. ${ }^{48,62}$

O tamoxifeno apresenta efeitos indesejáveis, como resistência ao fármaco durante um longo tempo de terapia e não é efetivo contra tumores independentes de hormônios. Uma das formas mais comuns de se tratar o câncer é através da quimioterapia. Nas últimas décadas 
<smiles>[R]c1ccc(C(=C(CC)c2ccccc2)c2ccc(OCCN(C)C)cc2)cc1</smiles>

\section{$\mathrm{R}=\mathrm{H}$ Tamoxifeno}

\section{$\mathrm{R}=\mathrm{OH}$ Hidroxitamoxifeno}

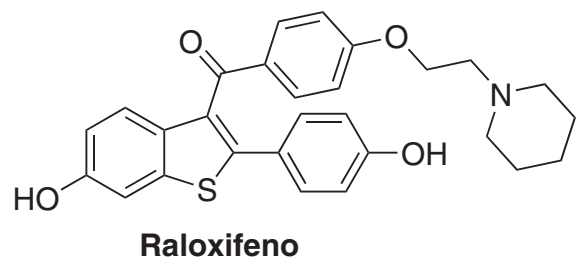

Figura 3. Estruturas químicas do tamoxifeno, hidroxitamoxifeno e raloxifeno

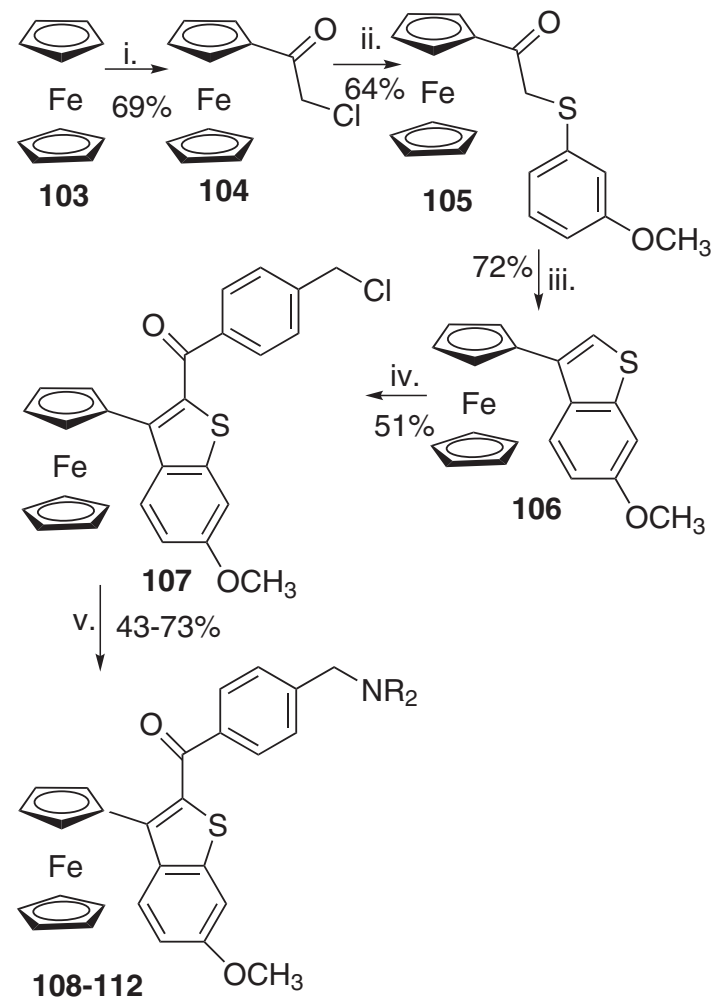

i. $\mathrm{AlCl}_{3} / \mathrm{ClCOCH} \mathrm{Cl}_{2} \mathrm{Cl}$

ii.t-BuOK /3-metoxibenzenotiol

iii.Amberliste 15

iv.1-n-BuLi

2-Cloreto de 4-clorometilbenzoil

$v \cdot \mathrm{R}_{2} \mathrm{NH} \cdot \mathrm{R}_{2} \mathrm{NH}=108-\mathrm{N}\left(\mathrm{CH}_{3}\right)_{2} \quad 109-\mathrm{N}$

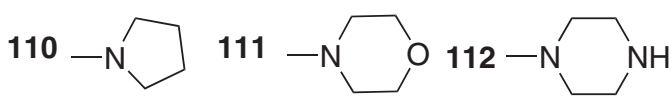

Esquema 22. Reação de síntese 2-acil-3-ferrocenil benzo [b] tiofenos houve uma revolução na pesquisa de substâncias causada pela química organometálica. Muitas substâncias ferrocenil substituídas têm se mostrado eficientes como agentes antitumorais. ${ }^{48,63-69}$

Sintese de substâncias antitumorais

Inspirados pela atividade do raloxifeno como modulador de estrogênio seletivo, Ferreira e colaboradores elaboraram uma estratégia sintética visando obter novas substâncias ferrocenilbenzo[b] tiofenos 108-112. As substâncias sintetizadas foram testadas contra células tumorais humanas, sendo que todas apresentaram considerável atividade citotóxica. Dentre elas, a substância $112\left(\mathrm{IC}_{50}\right.$ entre 0,73 a $3,85 \mu \mathrm{M})$ mostrou maior eficácia, in vitro, como agente antitumoral. A sequência sintética para a síntese de 2-acil-3-ferrocenil benzo [b] tiofenos é mostrada no Esquema 22.70

Spencer et al. mostraram a síntese de uma mistura de isômeros (E)- e (Z)-3-ferrocenilmetilidano-1,3-di-hidro-2H-indol-2-ona 115 e 116 a partir de uma condensação Knovenagel de 1,3-di-hidro- $2 H$ -indol-2-ona com ferroceno carboxaldeído. Ambos isômeros apresentaram toxicidade, in vitro, contra melanoma B16 frente a linhagens de células Vero e inibiram a quinase VEGFR-2, com valores de $\mathrm{IC}_{50}$ de 200nM (Esquema 23)..$^{71}$
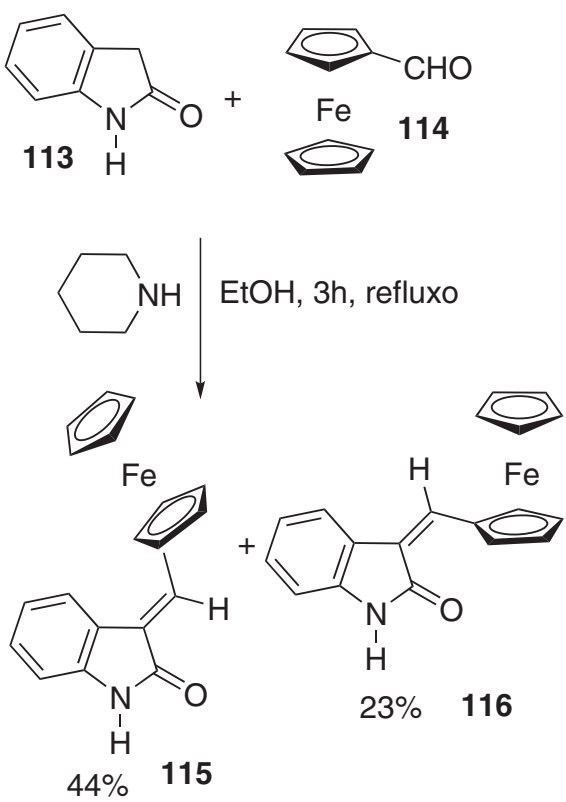

Esquema 23. Síntese de isômeros (E)- $e$ (Z)-3-ferrocenilmetilidano-1,3-di-hidro-2H-indol-2-ona

\section{CONCLUSÃO}

A descoberta do ferroceno impulsionou as pesquisas na química de organometálicos, principalmente, na Química Medicinal devido as suas excelentes propriedades, pois esse é uma substância estável, não tóxica e apresenta boa propriedade redox. A inserção de um grupo ferroceno em um fármaco conhecido pode ser uma alternativa para aumentar a atividade biológica e o espectro de ação.

Em especial, ferrocifenos têm se mostrado bons candidatos na substituição do tamoxifeno no tratamento de câncer. Da mesma forma, tem-se estudado compostos antimaláricos, antibacterianos, antifúngicos e inibidores de acetilcolinesterase contendo grupo ferroceno com o objetivo de se obter substâncias mais eficazes.

\section{REFERÊNCIAS}

1. Pauson, P. L.; J. Organomet. Chem. 2001, 3-6, 637. 
2. Kealy, T. J.; Pauson, P. L.; Nature 1951, 168, 1040.

3. Rosenblum, M.; J. Organomet. Chem. 2001, 13-15, 637.

4. Stavaren, D.; Nolte, N.; Chem. Rev. 2004, 104, 5931.

5. Corry, A. J.; Mooney, A.; O’Sullivan, D.; Kenny, P. T. M.; Inorg. Chim. Acta 2009, 362, 2957.

6. Lee, T. Y.; Chiang, P. R.; Tsai, M. C.; Lin, C. Y.; Huang, J. H.; J. Mol. Struct. 2009, 935, 102.

7. Federman, A.; Lanchote, A. D.; Quim. Nova 1998, 21, 214.

8. Francisco, A. I.; Vargas, M. D.; Revista Virtual de Química 2010, 2, 118.

9. Nesmeyanov, A. N.; Kochetkova, N. S.; Russ. Chem. Rev. 1974, 43, 710.

10. Fery-Forgues, S.; Delavaux-Nicot, B.; J. Photochem. Photobiol., A 2000, 132, 137.

11. Shang, Y. J.; Wu, D. L.; Wang, Y. L.; Shen, L. J.; Chin. J. Chem. 2005, $23,14$.

12. Máñez, R. M.; Sancenón, F.; Chem. Rev. 2003, 103, 4420.

13. Carolan, N.; Forster, R. J.; Ó'Fágáin, C.; Bioconjugate Chem. 2007, 18, 524.

14. Fish, R. H.; Jaouen, G.; Organometallics 2003, 22, 2166.

15. Hu, X.; Zheng, Z.; Org. Lett. 2005, 7, 419.

16. Neuse, E. W.; Nature 1964, 204, 179.

17. Liu, X.; Basu, A.; J. Am. Chem. Soc. 2009, 131, 5718.

18. Immoos, C. E.; Lee, S. J.; Grinstaff, M. W.; J. Am. Chem. Soc. 2004, $126,10814$.

19. Chatelain, G.; Brisset, H.; Chaix, C.; New J. Chem. 2009, 33, 1139

20. Champdoré, D. M.; Fabio, D. G.; Messere, A.; Montesarchio, D.; Piccialli, G.; Loddo, R.; Colla. L. M.; Colla, L. P.; Tetrahedron 2004, 60,6555 .

21. Abd-Elzaher, M. M.; El-shiekh, S.; Eweis, M.; Appl. Organomet. Chem. 2006, 20, 597.

22. Itoh, T.; Shirakami, S.; Ishida, N.; Yamashita, Y.; Yoshida, T.; Kim, H. S.; Wataya, Y.; Bioorg. Med. Chem. Lett. 2000, 10, 1657.

23. Yeary, R. A.; Toxicol. Appl. Pharmacol. 1969, 15, 666.

24. Leung, H. W.; Hallesy, D. W.; Shott, L. D.; Murray, F. J.; Paustenbach, D. J.; Toxicol. Lett. 1987, 38, 103.

25. Nikula, K. J.; Sun, J. D.; Barr, E. B.; Bechtold, W. E.; Haley, P. J.; Benson, J. M.; Eidson, A. F.; Burt, D. G.; Dahl, A. R.; Henderson, R. F.; Chang, I. Y.; Mauderly, J. L.; Dieter, M. P.; Hobbs, C. H.; Fundamental and Applied Toxicology 1993, 21, 127.

26. Edwards, E. I.; Epton, R.; Marr, G.; J. Organomet. Chem. 1976, 107, 351.

27. Silveira, G. P.; Nome, F.; Gesser, J. C.; Sá, M. M.; Terenzi, H.; Quim. Nova 2006, 29, 844.

28. Wise, R.; J. Antimicrob. Chemother. 2003, 51, Suppl. S2, ii5.

29. Edwards, E. I.; Epton, R.; Marr, G.; J. Organomet. Chem. 1976, 122, 50.

30. Eicher, T.; Hauptmann. S.; The Chemistry of Heterocycles, $2^{\text {nd }}$ ed., Wiley-VCH Verlag GmbH \& Co. KGaA: Saarbrücken e Leipzig, 2003.

31. Long, B.; He, C.; Yang, Y.; Xiang, J.; Eur. J. Med. Chem. 2010, 45, 1181.

32. Pereira, C. M. P.; Quina, F. H.; Silva, F. A. N.; Emmerich, D. J.; Machulek, A.; Mini-Rev. Org. Chem. 2008, 5, 331.

33. Pizzuti, L.; Piovesan, L. A.; Flores, A. F. C.; Quina, F. H.; Pereira, C. M. P.; Ultrason. Sonochem. 2009, 16, 728.

34. Pizzuti, L.; Martins, P. L. G.; Ribeiro, B. A.; Quina, F. H.; Pinto, E.; Flores, A. F. C.; Venzke, D.; Pereira, C. M. P.; Ultrason. Sonochem. 2010, 17, 34 .

35. Martins, M. A. P.; Pereira, C. M. P.; Moura, S.; Frizzo, C. P.; Beck, P; Zanatta, N.; Bonacorso, H. G.; Flores, A. F. C.; J. Heterocycl. Chem. 2007, 44, 1195

36. Martins, M. A. P.; Pereira, C. M. P.; Beck, P.; Machado, P.; Moura, S.; Teixeira, M. V. M.; Bonacorso, H. G.; Zanatta, N.; Tetrahedron Lett. 2003, 44, 6669.

37. Ju, Y.; Varma, R. S.; Tetrahedron Lett. 2005, 46, 6011.

38. Sheldon, R. A.; Green Chem. 2007, 9, 1273.
39. Fang, J.; Jin, Z.; Li, Z.; Liu, W.; J. Organomet. Chem. 2003, 674, 1.

40. Zhang, J.; Appl. Organomet. Chem. 2008, $22,7$.

41. Damljanović, I.; Vukićević, M.; Radulović, N.; Palić, R.; Ellmerer, E.; Ratković, Z.; Joksović, M. D.; Vukićević, R. D.; Bioorg. Med. Chem. Lett. 2009, 1093, 1095.

42. Joksović, M. D.; Ratković, Z.; Vukićević, M.; Vukićević, R. D.; Synlett 2006, 16, 2581

43. Stoppa, M. A.; Casemiro, L.; Vinholis, A.; Cunha, W.; Silva, M.; Martins, C.; Quim. Nova 2009, 32, 498.

44. Pereira, D. G.; Quim. Nova 2007, 30, 171.

45. Melo, J. O. F.; Donnici, C. L.; Augusti, R.; Ferreira, V. F.; Souza, M. C. B. V.; Ferreira, M. L. G.; Cunha, A. C.; Quim. Nova 2006, 29, 569.

46. Jin, Z.; Huo, A.; Liu, T.; Hu, Y.; Liu, J.; Fang, J.; J. Organomet. Chem. 2005, 690, 1226.

47. Biot, C.; François, N.; Maciejewski, L.; Brocard, J.; Poulain, D.; Bioorg. Med. Chem. Lett. 2000, 10, 840.

48. Fouda, M.; Abd-Elzaher, M.; Abdelsamaia, R.; Labib, A. A.; Appl. Organomet. Chem. 2007, 21, 619.

49. Cunico, W.; Carvalho, S. A.; Gomes, C. R. B.; Marques, G. H.; Revista Brasileira de Farmácia 2008, 89, 49.

50. Guillon, J.; Moreau, S.; Mouray, E.; Sinou, V.; Forfar, I.; Fabre, S. B.; Desplat, V.; Millet, P.; Parzy, D.; Jarry, C.; Grellier, P.; Bioorg. Med. Chem. 2008, 16, 9133.

51. Wu, X.; Wilairat, P.; Go, M. L.; Bioorg. Med. Chem. Lett. 2002, 12, 2299.

52. Biot, C.; Daher, W.; Chavain, N.; Fabdeur, T.; Khalife, J.; Dive, D.; Clercq, E.; J. Med. Chem. 2006, 49, 2845.

53. Biot, C.; Dessolin, J.; Ricard, I.; Dive, D.; J. Organomet. Chem. 2004, $689,4680$.

54. Wu, X.; Tiekink. E. R.; Kotstetski, I.; Kocherginsky, N.; Tan, A. L.; Khoo, S. B.; Wilairat, P.; Go, M.; Eur. J. Pharm. Sci. 2006, 27, 176

55. Biot, C.; Caron, S.; Maciejewski, L. A.; Brocard, J. S.; J. Labelled Compd. Radiopharm. 1998, XLI, 911.

56. Almeida, O.; Arquivos de Neuro-psiquiatria 1998, 56, 688.

57. Trevisan, M. T. S.; Macedo, F. V. V.; Quim. Nova 2003, 26, 301.

58. Contelles, J. M.; Léon, R.; Morales, E.; Villarroya, M.; García, A. G.; Tetrahedron Lett. 2004, 45, 5203.

59. Hügel, H. M.; Molecules 2009, 14, 4936.

60. Souza, M.; Quim. Nova 2003, 26, 366.

61. Melo, E. B.; Bruni A. T.; Ferreira, M. M. C.; Quim. Nova 2006, 29, 555.

62. Krishna, A. D. S.; Panda, G.; Kondapi, A. K.; Arch. Biochem. Biophys. 2005, 438, 206.

63. Zekri, O.; Hillard, E. A.; Top, S.; Vessières, A.; Pigeon, P.; Plamont, M. A.; Huché, M.; Boutamine, S.; McGlinchey, M. J.; Müller-Bunz, H.; Jaouen, G.; Dalton Trans. 2009, 22, 4318.

64. Joksović, M. D.; Marković, V.; Juranić, Z. D.; Stanojković, T.; Jovanović, L. S.; Damljanović, I. S.; Szécsényi, K. M.; Todorović, N.; Trifunović, S.; Vukićević, R. D.; J. Organomet.Chem. 2009, 694, 3935.

65. Pan, X. H.; Liu, X.; Zhao, B. X.; Xie, Y. S.; Shin, D. S.; Zhang, S. L.; Zhao, J.; Miao, J. Y.; Bioorg. Med. Chem. 2008, 16, 9093.

66. Top, S.; Vessières, A.; Leclercq, G.; Quivy, J.; Tang, J.; Vaissermann, J.; Huché, M.; Jaouen, G.; Chem.--Eur. J. 2003, 9, 5223.

67. Harding, M. M.; Mokdsi, G.; Curr. Med. Chem. 2000, 7, 1289.

68. Köpf-Maier, P.; Köpf, H.; Chem. Rev. 1987, 87, 1137.

69. Nguyen, A.; Marsaud, V.; Bouclier, C.; Top, S.; Vessieres, A.; Pigeon, P.; Gref, R.; Legrand, P.; Jaouen, G.; Renoir, J. M.; Int. J. Pharm. 2008, 347, 128

70. Ferreira, A. P.; Silva, J. L. F.; Duarte, M. T.; Piedade, M. F. M.; Robalo, M. P.; Harjivan, S. G.; Marzano, C.; Gandin, V.; Marques, M. M.; Organometallics 2009, 28, 5412.

71. Spencer, J.; Mendham, A. P.; Kotha, A. K.; Richardson, S. C. W.; Hillard, E. A.; Jaouen, G.; Male, L.; Hursthouse, M. B.; Dalton Trans. 2009, $6,918$. 